\title{
Pattern and Presentation of Thyro-Cardiac Disease among Patients with Hyperthyroidism Attending a Tertiary Hospital in Ethiopia: A Cross Sectional Study
}

\author{
Hailu Abera Mulatu ${ }^{1 *}$
}

\section{OPEN ACCESS}

Citation: Hailu Abera Mulatu.Pattern and Presentation of Thyro-Cardiac Disease among Patients with Hyperthyroidism Attending a Tertiary Hospital in Ethiopia: A Cross Sectional Study. Ethiop J Health Sci. 2018;29(1):887.

doi:http://dx.doi.org /10.4314/ejhs.v29i1.10

Received: July 30, 2018

Accepted:August 1, 2018

Published: January 1, 2019

Copyright: (c) 2018 Hailu Abera

Mulatu.This is an open access article distributed under the terms of the Creative Commons Attribution License, which permits unrestricted use, distribution, and reproduction in any medium, provided the original author and source are credited. Funding:St. Paul's Hospital Millennium Medical College.

Competing Interests: The authors declare that this manuscript was approved by all authors in its form and that no competing interest exists.

Affiliation and Correspondence:

${ }^{1}$ Department of Internal Medicine, Cardiology Unit, St. Paul's Hospital Millennium Medical College, Addis Ababa, Ethiopia*Email:dhailu2001@gmail .com

\begin{abstract}
BACKGROUND:Thyro-cardiac disease describes the existence of a combination of thyroid toxicity and significant heart disease in an individual patient. The frequent manifestations of thyro-cardiac disease are hypertension, atrial flutter or fibrillation, pulmonary hypertension and dilated cardiomyopathy. The aim of the study was to determine the pattern and presentation of cardiovasculardiseases in patients with hyperthyroidism on follow-up at St. Paul's Hospital endocrine clinic.

METHODS:It was a hospital based cross sectional study that evaluated hyperthyroid patients' on follow-up at St. Paul's Hospital for cardiovascular diseases from May $1^{\text {st }} 2017$ to October $31^{\text {st }} 2017$. Theyhad focused history, physical examination, electrocardiographic and echocardiographic evaluation.

RESULTS: A total of 146 hyperthyroid patients on follow-up were included in the study. The mean age was 47.2 years and females accounted for $93.2 \%$ of patients. The mean duration of symptoms before presentation was 42 months. The frequent causes of hyperthyroidism were toxic multi-nodular goitre (88.4\%), Graves, disease (6.8\%) and toxic adenoma (2.1\%). Sixteen (11\%) patients had atrial fibrillation and 71 (48.6\%) had hypertension. Thyrocardiac disease was detected in $46.6 \%$ of patients. The frequent abnormalities were left ventricular hypertrophy (14.4\%), mild diastolic dysfunction (10.9\%), moderate to severe mitral regurgitation (8.9\%), pulmonary hypertension with or without right ventricular dysfunction (8.2\%) and dilated cardiomyopathy (4.1\%). CONCLUSION: Cardiovascular disease was frequent among patients with hyperthyroidism. The commonest abnormalities were systemic hypertension, pulmonary hypertension with or without isolated right sided heart failure, atrial fibrillation and dilated cardiomyopathy. KEYWORDS: Cardiovascular disease, hyperthyroidism, pattern, presentation, thyro-cardiac disease
\end{abstract}

\section{INTRODUCTION}

Hyperthyroidism is defined as a clinical condition that results from abnormally high serum thyroid hormone levels (1). Even a slight increment in thyroid hormone levels above normal can change the physiologic state of cardiovascular function, mainly due to the effects of tri-iodothyronine (T3) on the cardiovascular system. It 
causes decreased systemic vascular resistance and increased resting heart rate, left ventricular contractility, blood volume and cardiac output. Thus, cardiovascular manifestations are common findings of hyperthyroidism (2).

In Ethiopia so far, few studies were conducted on the clinical manifestations of hyperthyroidism and patients' response to available treatment modalities before two decades $(3,4)$. Currently, there is limited data on hyperthyroidism in Ethiopia and no study has looked into the cardiovascular abnormalities associated with hyperthyroidism. Studies from other African countries showed that cardiovascular abnormalities are common clinical presentations of patients with hyperthyroidism with prevalence ranging between $8-22 \%$, leading to increased morbidity and mortality in this group of patients $(5,6)$.

Previous studies from Ethiopia included very small sample sizes and cannot represent patients with hyperthyroidism. Current knowledge of the extent of cardiac complications of hyperthyroidism is valuable in designing strategies to combat burden of the disease in the community. Moreover, with early diagnosis and effective treatment of the disease, we can revert most of the cardiac complications. Thus, we examined the pattern and presentation of cardiovascular abnormalities among Ethiopian hyperthyroid patients on follow up at St. Paul's Hospital.

\section{PATIENTS AND METHODS}

The study was conducted at St. Paul's Hospital, the second largest public hospital in Addis Ababa, Ethiopia. A total of about 400 registered patients with hyperthyroidism were on follow-up in the hospital. Across-sectional study design was used to evaluate the cardiovasculardiseases associated with hyperthyroidism among patients on followup at St. Paul's Hospital from May $1^{\text {st }} 2017$ to October $31^{\text {st }} 2017$. The study subjects were patients who were diagnosed with hyperthyroidism aged 15 years and above. They were recruited consecutively when they were newly enrolled or came for follow-up at the endocrine unit ofSt. Paul's Hospital having clinical and biochemical thyroid function assessments. Newly diagnosed subjects had focused history, physical examination, complete blood count, fasting blood sugar, lipid profile, thyroid function test, electrocardiography (ECG) and echocardiographic examination. For caseson follow-up, baseline medical history, biochemical tests, ECG and echocardiographic examinations were reviewed from their registries. ECG and echocardiographic examinations older than six months were updated.

Sample Size and sampling procedure:Sample size calculation for this study was performed using the single population proportion formula and finite number of hyperthyroid patients on follow-up. Considering the total number of patients with hyperthyroidism on follow-up at St. Paul's Hospital as 400, 15\% (range 8-22\%) for the mean prevalence of thyro-cardiac disease among adults in Sub-Saharan Africa, 5\% margin of error, 95\% confidence interval and 10\% nonresponse rate, the calculated total number of patients was 146. Using a structured questionnaire, the socio-demographic, signs and symptoms of hyperthyroidism, biochemical, electrocardiographic and echocardiographic findings of all patients were collected until the sample size was attained. In this study, patients with either persistent atrial fibrillation or signs of cardiac insufficiency on admission were classified as thyro-cardiacs, whether or not there was associated organic cardiovascular disease. Those with hyperthyroidism who did not meet these standards were classified as non-thyro-cardiacs and were used as controls.

Data processing and analysis:Data were entered into EPI INFO version 6 and exported to SPSS version 20 statistical software for analysis. Frequencies and proportions were used to summarize the data while tables and graphs were used for data presentation. Proportions of categorical variables were compared using Pearson chi-square test and significant association was considered when $p$-value was $<0.05$.

Ethical clearance was obtained from the Institutional Review Board of St. Paul's Hospital Millennium Medical College. Informed consent was obtained from each patient, and those who volunteered were included in the study. Each patient's information was collected using a

DOI: http://dx.doi.org/10.4314/ejhs.v29i1.10 
structured questionnaire and did not contain patient's name or registration number and kept confidential.

\section{RESULTS}

A total of $146(48.7 \%)$ hyperthyroid patients on follow-up were included in the study. The mean age of the study participants was $47.2 \pm 15.2$ years. Females accounted for $93.2 \%$ and the commonest affected age group was 41-60 years in $47.9 \%$ followed by $21-40$ years in $29.5 \%$ of the patients (Figure 1). The mean duration of symptom onset and duration since diagnosis was $42 \pm 28.8$ and $30 \pm 26.4$ months respectively. The frequent causes of hyperthyroidism were toxic multi-nodular goiter in 129(88.4\%), Graves' disease in $10(6.8 \%)$ and toxic adenoma in $3(2.1 \%)$ of thepatients. In addition to the hyperthyroidism, an unrelated condition affecting the heart was present. The abnormalities included degenerative heart disease $(2.1 \%)$, rheumatic valvular disease $(1.4 \%)$ and ischemic disease $(0.7 \%)$. The frequent comorbidities were type 2 diabetes mellitus in 12(8.2\%), bronchial asthma in $5(3.4 \%)$ and $\mathrm{HIV}$ in $4(2.7 \%)$ patients. The majority $(82.8 \%)$ had no comorbid illness. The mean heart rate and mean systolic blood pressure during the evaluation were 101 beats per minute and $134 \mathrm{mmHg}$ respectively. Sixteen (11\%) patients had atrial fibrillation and $130(89 \%)$ patients were in sinus rhythm. Hypertension was diagnosed in $71(48.6 \%)$ patients with a systolic blood pressure of $140 \mathrm{mmHg}$ or more or diastolic blood pressure of $90 \mathrm{mmHg}$ or more. Microcytic and hypochromic anemia was observed in 13 $(8.9 \%)$ patients.

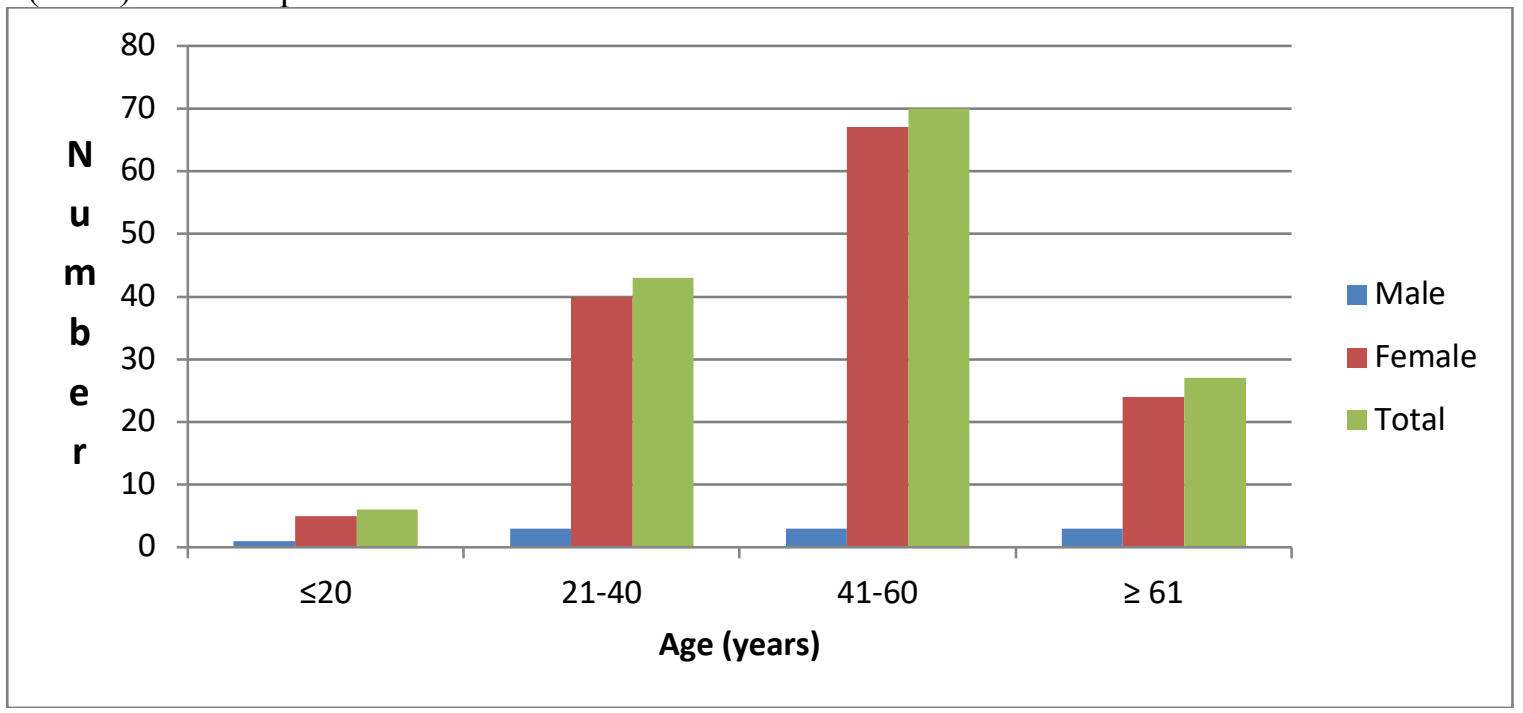

Figure 1: Age-sex distribution of study patients $(n=146)$

Thyro-cardiac disease (cardiac disease associated with hyperthyroidism, excluding hypertension) was present in 68(46.6\%) patients (Figure 2). Heart failure with reduced ejection fraction and isolated right sided heart failure was diagnosed in $6(4.1 \%)$ patients each (Table 1). The frequent presenting symptoms and signs of heart failure were exertional dyspnea in $80(54.8 \%)$, followed by elevated jugular venous pressure in $23(15.8 \%)$ and nocturnal cough in $20(13.7 \%$ ) (Table 2$)$. 


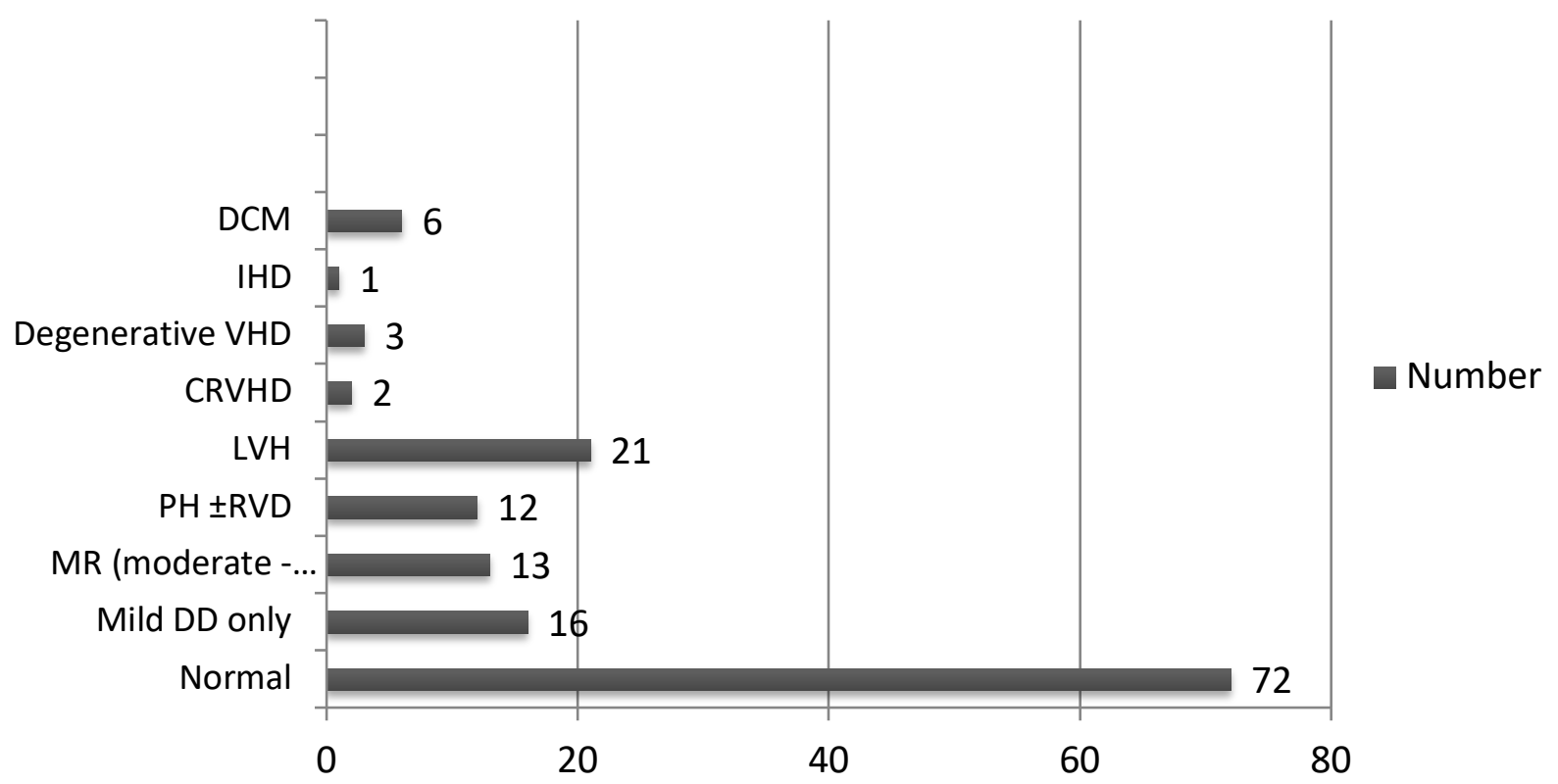

CRVHD: chronic rheumatic valvular heart disease, DCM: dilated cardiomyopathy, DD: diastolic dysfunction,IHD: ischemic heart disease, LVH: left ventricular hypertrophy, MR: mitral regurgitation, PH: pulmonary hypertension, RVD: right ventricular dysfunction, VHD: valvular heart disease

Figure 2: Types of cardiovascular abnormalities associated with hyperthyroidism $(n=146)$

Table 1: Baseline characteristics of study patients $(n=146)$

\begin{tabular}{|c|c|}
\hline Characteristics & Value, $\mathrm{n}(\%)$ \\
\hline Age, mean \pm SD (years) & $47.2 \pm 15.2$ \\
\hline Female sex, $\mathrm{n}(\%)$ & $136(93.2)$ \\
\hline Duration of symptoms, mean \pm SD (months) & $42.0 \pm 28.8$ \\
\hline \multicolumn{2}{|l|}{ Follow up status of patients } \\
\hline New & $25(17.1)$ \\
\hline Follow up & $121(82.9)$ \\
\hline Duration since diagnosis, mean $\pm \mathrm{SD}$ (months) & $30.0+26.4$ \\
\hline Heart failure present, $\mathrm{n}(\%)$ & $27(18.5)$ \\
\hline \multicolumn{2}{|l|}{ Cause of hyperthyroidism, $\mathrm{n}(\%)$} \\
\hline Toxic multi-nodular goiter & $129(88.4)$ \\
\hline Graves' disease & $10(6.8)$ \\
\hline Toxic adenoma & $3(2.1)$ \\
\hline Thyroiditis & $2(1.4)$ \\
\hline Thyroid cancer & $2(1.4)$ \\
\hline Heart rate at initial presentation, mean $\pm \mathrm{SD}$ (bpm) & $101 \pm 18$ \\
\hline \multicolumn{2}{|l|}{ Blood pressure, mean $\pm \mathrm{SD}(\mathrm{mmHg})$} \\
\hline SBP & $134 \pm 22.6$ \\
\hline DBP & $75.8 \pm 12.2$ \\
\hline Hypertension, $\mathrm{n}(\%)$ & $71(48.6)$ \\
\hline Anemia, n (\%) & $13(8.9)$ \\
\hline Diabetes mellitus, n (\%) & $12(8.2)$ \\
\hline
\end{tabular}

DOI: http://dx.doi.org/10.4314/ejhs.v29i1.10 
Comorbid condition, n (\%)

HIV

$4(2.7)$

Bronchial asthma

Dyslipidemia

Degenerative valve disease

$3(2.1)$

Rheumatic heart disease

Ischemic heart disease

$1(0.7)$

Other

None $121(82.8)$

Heart rhythm, n (\%)

Sinus rhythm

$130(89)$

Atrial fibrillation

$16(11)$

Anemia was defined as hemoglobin $<13 \mathrm{gm} / \mathrm{dl}$ for males and $<12 \mathrm{gm} / \mathrm{dl}$ for females; HIV: Human Immuno-deficiency Virus; SD: standard deviation; DBP: diastolic blood pressure; SBP: systolic blood pressure

Table 2: Cardiovascular manifestations of patients with hyperthyroidism $(\mathrm{n}=146)$

\begin{tabular}{ll}
\hline Symptom or sign & Frequency (\%) \\
& \\
\hline Exertional dyspnea & $80(54.8)$ \\
Nocturnal cough & $20(13.7)$ \\
Orthopnea & $11(7.5)$ \\
Paroxysmal nocturnal dyspnea & $10(6.8)$ \\
Pulmonary rales or pleural effusion & $19(13)$ \\
Elevated jugular venous pressure & $23(15.8)$ \\
S3 gallop & $5(3.4)$ \\
Hepatomegaly & $19(13)$ \\
Hepato-jugular reflux & $19(13)$ \\
Pitting edema & $27(18.5)$ \\
\hline
\end{tabular}

Echocardiographic abnormalities of patients revealed mild left ventricular hypertrophy $(22.6 \%)$, pulmonary hypertension $(30.1 \%)$ and mild diastolic dysfunction $(39.7 \%)$. The most frequent and significant valvular insufficiencies were tricuspid regurgitation (21.2\%), mitral regurgitation $(17.8 \%)$ and aortic regurgitation (3.4\%) (Table 3).
Table 3: Echocardiographic and Doppler findings of study patients $(\mathrm{n}=146)$.

\begin{tabular}{|c|c|}
\hline Measurement & $\begin{array}{l}\text { Mean } \pm \text { SD [range] } \\
\text { or number }(\%)\end{array}$ \\
\hline $\begin{array}{l}\text { Left ventricle end-diastolic } \\
\text { dimension (mm) }\end{array}$ & $44.6 \pm 5.9[35-73]$ \\
\hline $\begin{array}{l}\text { Left ventricular ejection } \\
\text { fraction }(\%)\end{array}$ & $63.3 \pm 8.9[25-82]$ \\
\hline \multicolumn{2}{|l|}{ Left ventricular hypertrophy } \\
\hline Mild & $33(22.6)$ \\
\hline Moderate & $2(1.4)$ \\
\hline Severe & $1(0.7)$ \\
\hline TAPSE (mm) & $21.0 \pm 3.5[11-32]$ \\
\hline \multicolumn{2}{|l|}{ Pulmonary hypertension } \\
\hline Mild & $14(9.6)$ \\
\hline Moderate & $16(11.0)$ \\
\hline Severe & $14(9.6)$ \\
\hline \multicolumn{2}{|l|}{ Mitral regurgitation } \\
\hline Mild & $28(19.2)$ \\
\hline Moderate & $16(11.0)$ \\
\hline Severe & $10(6.8)$ \\
\hline \multicolumn{2}{|l|}{ Aortic regurgitation } \\
\hline Mild & $18(12.3)$ \\
\hline Moderate & $5(3.4)$ \\
\hline Severe & - \\
\hline \multicolumn{2}{|l|}{ Tricuspid regurgitation } \\
\hline Mild & $17(11.6)$ \\
\hline Moderate & $19(13.0)$ \\
\hline Severe & $12(8.2)$ \\
\hline \multicolumn{2}{|l|}{ Diastolic dysfunction } \\
\hline Mild & $58(39.7)$ \\
\hline Moderate & $5(3.4)$ \\
\hline Severe & - \\
\hline
\end{tabular}

DOI: http://dx.doi.org/10.4314/ejhs.v29i1.10 
Thyro-cardiac disease was three times more common in patients with atrial fibrillationthansinus rhythm (p-value $<0.001$ ). However, demographic and clinical profiles (age, sex, duration of symptom, hypertension, diabetes mellitus and anemia) were not associated with thyro-cardiac disease (Table 4).

Table 4: Demographicand clinical predictors of patients with or withoutthyro-cardiac disease $(n=146)$

\begin{tabular}{llllll}
\hline Variable & $\begin{array}{l}\text { Overall } \\
\mathbf{n} \%)\end{array}$ & $\begin{array}{l}\text { TCDs } \\
\text { present, } \\
(\mathbf{\%})\end{array}$ & $\begin{array}{l}\text { No TCDs } \\
\text { present, } \mathbf{n}(\%)\end{array}$ & $\begin{array}{l}\text { OR (95\% } \\
\text { CI) }\end{array}$ & p-value \\
\hline Age $\geq 60$ years & $35(24.0)$ & $11(7.5)$ & $24(16.4)$ & $0.8(0.4-1.4)$ & 0.3 \\
Female sex & $136(93.1)$ & $36(24.6)$ & $100(68.5)$ & $0.7(0.2-2.7)$ & 0.5 \\
Duration of symptom $\geq 24$ months & $117(80.1)$ & $32(21.9)$ & $85(58.2)$ & $0.7(0.4-1.6)$ & 0.3 \\
Hypertension (BP $\geq 140 / 90 \mathrm{mmHg})$ & $71(48.6)$ & $16(10.9)$ & $55(37.7)$ & $0.8(0.4-1.3)$ & 0.2 \\
Diabetes mellitus present & $12(8.2)$ & $4(2.7)$ & $8(5.5)$ & $1.3(0.6-3.1)$ & 0.4 \\
Anemia $(H b ;$ male $<13$ gm/dl or female & $13(8.9)$ & $6(4.1)$ & $7(4.8)$ & $1.9(0.9-3.7)$ & 0.08 \\
$<12$ gm/dl) & & & & & \\
Comorbidity present & $25(17.1)$ & $4(2.7)$ & $21(14.4)$ & $0.6(0.2-1.5)$ & 0.2 \\
Heart rate $\geq 120$ bpm & $30(20.5)$ & $8(5.5)$ & $22(15.1)$ & $1.0(0.5-2.0)$ & 0.5 \\
Atrial fibrillation present & $16(10.9)$ & $11(7.5)$ & $5(3.4)$ & $\mathbf{3 . 3}(2.1-5.3)$ & $<\mathbf{0 . 0 0 1}$ \\
\hline
\end{tabular}

Bpm: beats per minute, CI: confidence interval, Hb: hemoglobin, $N$ : number, OR: odds ratio, TCDs: thyro-cardiac disease

\section{DISCUSSION}

This is the first echocardiographic based study conducted among hyperthyroid patients in Ethiopia. The majority of the patients belonged to the middle age group of 41-60 years. The mean duration of symptom before diagnosis was 42 months, and the majority of the patients had toxic multi-nodular goiter as a cause of hyperthyroidism. Echocardiographic abnormalities were detected in half $(50.7 \%)$ of the patients. The study showed that $27(18.5 \%)$ patients had heart failure at initial presentation with the most common cardiovascular manifestations being exertional dyspnea (54.8\%), pitting edema (18.5\%) and elevated jugular venous pressure $(15.8 \%)$. Nearly half $(48.6 \%)$ of the patients had hypertension, and atrial fibrillation was seen in $11 \%$ of patients. Six (4.1\%) patients had heart failure with reduced ejection fraction while another $6(4.1 \%)$ patients had isolated right sided heart failure. Pulmonary hypertension with pulmonary artery systolic pressure of $35 \mathrm{mmHg}$ or more was found in 54(37\%) patients.

Consistent with other hospital-based studies (7$10)$, the most frequently affected age group with hyperthyroidismwas 41-60 years withpredominance in females. In addition, patients present after a long period of symptom duration. This mightbe due to lack of awareness about the symptoms or low perceived need for healthcare,financial constraints, missed diagnoses from ignorance on the part of primary healthcare providers who these patients usually present to initially, or preferences of other alternative treatments like traditional medicine until the disease gets worsened $(11,12)$.

A study conducted over two decades ago in Ethiopia (12) reported that the most common cause of hyperthyroidism was GD followed by TMNG and TA. However, our finding and studies from other countries $(8,13)$ revealed that TMNG, followed by GD and TA, was the most common causes of hyperthyroidism. This disparity might be due to a changing epidemiologic pattern of the disease and needs further studies.

Through its physiologic and hemodynamic effects,hyperthyroidism causes cardiac complications in individuals with structurally normal hearts or can complicate preexisting cardiac disease. It increases heart rate, blood volume, and cardiac contractility, as well as decreases systemic vascular resistance, all of which increase cardiac output (14). The prevalence of thyro-cardiac disease in our patients was higher $(46.6 \%)$ than reports from other Sub-Saharan African countries, which ranges between $16-27 \%(7,8,14,15)$. The higher prevalence of thyro-cardiac disease in our study might be

DOI: http://dx.doi.org/10.4314/ejhs.v29i1.10 
related to the inclusion of mild (grade I) diastolic dysfunction and mild left ventricular hypertrophy, which were not included in the other studies. By excluding these two conditions, the prevalence of thyro-cardiac disease would have been $24.7 \%$. Consistent with other studies from low income countries $(7,8), 23 \%$ of our patients had heart failure at initial presentation. This figure is higher than reports from high income countries $(2,9)$, most likely related to very late presentation of our patients with a mean duration of 42 months compared to less than 35 months in the later. The magnitude of atrial fibrillation in our study was $11 \%$, which is slightly lower than other studies that reported prevalence of $14 \%$ to $31 \%(9,10,16)$. This might be explained by the differences in the methodology used, where we included patients on follow-up who might have spontaneously reverted atrial fibrillation to sinus rhythm after initiation of therapy and had no documented baseline electrocardiographic studies. However, the other studies included only treatment-naïve patients. Nevertheless, systematic reviews of numerous studies have reported similar prevalence of atrial fibrillation among hyperthyroid patients, i.e. between 10-28\% (17).

Echocardiographic studies by Mercé et al and Amigliato et al showed that $41 \%$ and $65 \%$ of their patients respectively had pulmonary hypertension. These figures are higher than the $30.1 \%$ in our current study. This may possibly be due to the fact that we included a significant proportion $(82.9 \%)$ of patients who were already on anti-thyroid drugs who might have resolution of their pulmonary hypertension after initiation of therapy. There was no association between pulmonary hypertension and the different causes of hyperthyroidism $(\mathrm{p}=0.5)$. Although there are possible explanations, the exact mechanism of how pulmonary hypertension occurs in patients with hyperthyroidism is not exactly known. The possible mechanisms are increased metabolism of vasodilator substances and decreased metabolism of vasoconstrictors, enhanced catecholamine sensitivity causing vasoconstriction, reduction in pulmonary artery compliance and increase in pulmonary vascular resistance $(18,19)$. In Contrary to other studies $(7,8,15)$, there is no statistically significant difference between thyrocardiacs and non-thyro-cardiacs with respect to age, sex, duration of symptom, hypertension, comorbidities and heart rate at initial presentation. Moreover, the pathologic causes, toxic multinodular goitre, Graves' disease or toxic adenoma were not associated with the development of thyro-cardiac disease. This might be due to relatively small sample size and needs further study.

Thestudy has several limitations.First, it is a single-center study with small number of newly diagnosed patients. Therefore, it may not represent the true picture in the community. Second, it lackscertain diagnostic tests to rule outother causes of pulmonary hypertension. Third, absence of follow-up data about the control of hyperthyroidism and cardiovascular disease.

In conclusion, cardiovascular abnormalities were frequent among patients with hyperthyroidism. The commonest abnormalities were systemic hypertension, pulmonary hypertension with or without isolated right sided heart failure, atrial fibrillation and dilated cardiomyopathy. Patients presentto hospitalafter prolonged durations of symptoms. Atrial fibrillation was more common in patients with thyro-cardiacs than non-thyrocardiacs. Therefore, it is prudent to screen all patients with hyperthyroidism for cardiovascular complications. Public awareness on symptoms and signs of hyperthyroidism should also be raised. Furthermore, multi-centric study with largersample size that looks into treatment outcome is warranted.

\section{ACKNOWLEDGMENT}

My heartfelt thanks go to my advisor Dr. Abdusamed Adem and Sr. MihretWoldemichael for their continuous support during data collection.

\section{REFERENCES}

1. Bahn RS, Burch HB, Cooper DS, Bahn RS, Burch HB, Cooper DS. Hyperthyroidism And Other Causes Of Thyrotoxicosis: Management Guidelines of The American Thyroid Association And American Association Of Clinical Endocrinologists. Endocr Pr. 2011;17(3):1-65.

2. Irwin Klein. Endocrine Disorders and Cardiovascular Disease. In: Douglas P. Zipes, Peter Libby, Robert O. Bonow EB, editor. Braunwald's Heart Disease: A Text Book of

DOI: http://dx.doi.org/10.4314/ejhs.v29i1.10 
Cardiovascular Medicine.10th ed. Philadelphia, PA: Library of Congress; 2015. p. 1798-805.

3. Abebe Bekele, Mensur Osman. Goitre in aTeaching Hospital in North Western Ethiopia. East CentAfrican $J$ Surg. 2006;11(2):21-7.

4. Jemal Abdulkadir, Abraham Besrat, Gebrehiwot Abraham and PG. Thyrotoxicosis in Ethiopian patients - a prospective study. Trans $R$ Soc Trop Med Hyg. 1982;76(2):500-2.

5. Danbauchi SS, Anumah FE, Alhassan MA OI, Issah HS OG. Thyrocardiac disease in Zaria. MedGenMed.2005;4:7(1):74. 2005;4(7 (1)):74.

6. Klein I, Danzi S. Thyroid Disease and the Heart. Circulation. 2007;116:1725-35.

7. Ogbera AO, Fasanmade OA I. The Scope O F Cardiac Complications Of Thyrotoxicosis in Lagos , Nigeria. Pak J Med Sci. 2007;23(5):671-5.

8. Hattaoui M El, Charei N, Mouniri M, Diouri A. Cardiothyrotoxicosis in the young adult in Marrakech: a report of 36 cases. Ann Cardiol d'Angéiologie. 2009;58:135-8.

9. Siu C, Yeung C, Lau C, Kung AWC, Tse H. Incidence, clinical characteristics and outcome of congestive heart failure as the initial presentation in patients with primary hyperthyroidism. Heart. 2007;93:483-7.

10. Mercé J, Ferrás S, Oltra C, Sanz, Esther et al. Cardiovascular abnormalities in hyperthyroidism: A prospective Doppler echocardiographic study. Am J Med. 2005; 118:126-31.
11. Begashaw B, Tessema F and GH. Healthcare Seeking Bihaviour in Southwest Ethiopia. PLoS One. 2016;11(9):e0161014.

12. Anagaw D Mebratie, Ellen Van de Poel, Zelalem Yilma, Degnet Abebaw et al. Healthcare-seeking behaviour in rural Ethiopia: evidence from clinical vignettes. BMJ Open. 2014;4:e004020.

13. Dahl P, Danzi S, Klein I. Thyrotoxic Cardiac Disease. Curr Heart Fail Rep. 2008;5:170-6.

14. Ogbera AO, Fasanmade O, Adediran O. Pattern of thyroid disorders in the southwestern region of Nigeria. Ethn Dis. 2007;17(2):327-30.

15. Boiro D, Diedhiou D, Niang B, Sow D, Mbodj M, Sarr A, et al. Hyperthyroidism in children at the University Hospital in Dakar (Senegal). Pan Afr Med J. 2017;28:10.

16. Armigliato $\mathrm{M}$, Paolini R, Aggio $\mathrm{S}$. Hyperthyroidism as a Cause of Pulmonary Arterial Hypertension: A Prospective Study. Angiology. 2006;57(5):600-6.

17. Biondi B KG. Cardiovascular involvement in patients with different causes of hyperthyroidism. Nat Rev Endocrinol. 2010;6:431-43.

18. Arvisi MM, Rianti MB, Arani GM, Orello PDELB, Ortesi MLB, Uariglia AG. Hyperthyroidism and pulmonary hypertension. Respir Med. 2002;96:215-20.

19. Vallabhajosula S, Radhi S, Alalawi R, Raj R, Nugent K, Cevik C. Hyperthyroidism and Pulmonary Hypertension: An Important Association. Am J Med Sci. 2011;342(6):50712. 